OPEN ACCESS

Edited by:

Umair Akram,

Jiangsu University, China

Reviewed by:

Choi Meng Leong,

UCSI University, Malaysia

Jian Ai Yeow

Multimedia University, Malaysia

${ }^{*}$ Correspondence:

Binyao Ning

janetning1107@163.com;

janetning@gmail.com

Specialty section:

This article was submitted to

Organizational Psychology,

a section of the journal

Frontiers in Psychology

Received: 06 December 2021 Accepted: 29 December 2021

Published: 20 January 2022

Citation:

Wang S, Ye Y, Ning B, Cheah J-H and

Lim X-J (2022) Why Do Some Consumers Still Prefer In-Store Shopping? An Exploration of Online

Shopping Cart Abandonment

Behavior. Front. Psychol. 12:829696. doi: 10.3389/fpsyg.2021.829696

\section{Why Do Some Consumers Still Prefer In-Store Shopping? An Exploration of Online Shopping Cart Abandonment Behavior}

\author{
Siqi Wang ${ }^{1}, \mathrm{Ye} \mathrm{Ye}^{2,3}$, Binyao Ning ${ }^{2 *}$, Jun-Hwa Cheah ${ }^{1}$ and Xin-Jean Lim ${ }^{4}$ \\ ${ }^{1}$ School of Business and Economics, Universiti Putra Malaysia, Serdang, Malaysia, ${ }^{2}$ Business School, Shaoguan University, \\ Shaoguan, China, ${ }^{3}$ College of Economics and Management, South China Agricultural University, Guangzhou, China, ${ }^{4}$ Centre \\ of Value Creation and Human Well-being, Faculty of Economics and Management, Universiti Kebangsaan Malaysia, Bangi, \\ Malaysia
}

Shopping cart abandonment remains a challenge for many e-retailers despite the continued growth of the e-commerce industry worldwide. However, the issue of online shopping cart abandonment (OSCA) has not been explored extensively in the literature. Grounded by the stimulus-organism-response (S-O-R) model, this study explores a sequential mediation model comprising consumers' wait for lower prices as an antecedent, hesitation at checkout and OSCA as mediators, perceived transaction inconvenience as a moderator, and decision to buy from a land-based retailer (DBLR) as an outcome. An online questionnaire was designed and distributed to 883 online consumers in Mainland China. Partial least squares-structural equation modeling (PLS-SEM) was employed to analyze the survey data. The results show that waiting for lower prices positively influences hesitation at checkout, and subsequently, impacts both OSCA and DBLR. Hesitation at checkout and OSCA play sequential mediating roles in the framework path. In addition, perceived transaction inconvenience strengthens the relationship between waiting for lower prices and hesitation at checkout. Overall, this study contributes to theory and serves as a guideline for e-retailers in reducing the OSCA rate.

\footnotetext{
Keywords: wait for lower price, hesitation at checkout, perceived transaction inconvenience, online shopping cart abandonment, decision to buy from a land-based retailer, stimulus-organism-response model
}

\section{INTRODUCTION}

By shifting many aspects of consumers' daily lives to online platforms, the COVID-19 pandemic has been an accelerator of e-commerce growth, especially that of online shopping. Research shows that about $79 \%$ of consumers preferred to order groceries online in 2020 , a $19 \%$ increase from 2019 (Inmar, 2020). Although the pandemic has driven the expansion of online shopping, the rate of online shopping cart abandonment (OSCA) is estimated to be as high as 95\% (Elkind, 2020), costing \$4.6 trillion in lost sales (Paterson, 2020). Thus, the growth of e-commerce does not mean the demise of brick-and-mortar retail. Data shows that $84 \%$ of sales occur in physical stores and $46 \%$ of consumers still prefer to shop and interact physically with sellers (Marian, 2021). This phenomenon can be explained by the need for live experiences (e.g., viewing, touching, interacting with physical products) $(33 \%)$ and immediacy 
(e.g., getting the item instantly) (13\%), which are forms of community and connection that online experiences are always lacking (Raydiant, 2021). Another study found that $65 \%$ of consumers claim to shop in-store to avoid shipping costs (Chad, 2021). In addition, the physical stores in China offer contactless payment (Daxue, 2021) and continue to meet consumer expectations for product quality, delivery, and brand values as compared purchasing via online. Thus, the recovery and strategy of traditional retail make it difficult for e-commerce to compete, as physical stores in China today provides consumer with an authentic and enjoyable customer experience.

With the resurgence of brick-and-mortar retailing, scholars have developed different understandings of online consumers' "non-buyer behavior." For example, according to Huang et al. (2018), OSCA is the final behavioral outcome that describes leaving an item in one's online shopping cart without completing the purchase. However, contrary findings are evident in the two major themes in OSCA research: purchase risk (i.e., financial risk and privacy risk) (Kukar-Kinney and Close, 2010; Xu and Huang, 2015; Kapoor and Vij, 2021) and technology-related inhibitors (i.e., website design and navigation structure) (Garaus, 2018; Kapoor and Vij, 2021). Also, recent research by Zhao et al. (2021) explored the impact of pop-up warning messages on consumers' OSCA behaviors. These studies have come to a limited understanding that consumers OSCA behavior is not the final outcome in decision-making; rather, there could be alternative behavioral decisions following OSCA, such as consumers' decision to buy from a land-based retailer (DBLR). This phenomenon may occur due to consumers' psychological characteristics or conflicts in the decision-making process (Mishra et al., 2021). Moreover, buying from physical stores helps consumers avoid shipping and handling costs, thereby achieving a lower total cost of ownership (Kukar-Kinney and Close, 2010). Therefore, it is timely and relevant for e-retailers to understand the factors that lead to OSCA (Huang et al., 2018; Jiang et al., 2021; Mishra et al., 2021) as well as its potential effect on DBLR behavior. The main purposes of this study are: (i) to identify the drivers of OSCA and how they influence consumers' decision to purchase from physical stores; and (ii) to explore the boundary conditions that influence the relationship between consumers' wait for lower prices and hesitation at checkout.

Although previous studies have shown that the price factor is a key inhibitor of purchase behavior (Kukar-Kinney and Close, 2010; Song, 2019), this notion has not been fully explored in the contexts of both OSCA and DBLR. Rajagopal (2019) defined price as an influential factor in consumers' preference, perception of value for money, purchase intention, consumption experience, and behavior. To some extent, price fluctuations can delay consumers' purchase decisions, which results in their hesitation to checkout (Kukar-Kinney and Close, 2010). This effect is said to be increasingly critical, especially during the COVID19 pandemic when consumers have been expected to reduce unnecessary spending to better cope with future uncertainty and risk (Jin et al., 2021). Thus, it seems a pertinent direction to examine consumers' perceived prices (i.e., their wait for lower prices) as the antecedent that influences hesitation at checkout and OSCA, thus resulting in DBLR.
Hesitation at checkout, in turn, is perceived as consumers' espousal of additional processing time to delay purchases before making a final purchase decision online (Cho et al., 2006). A consumer's hesitation during the purchasing process can lead to an unpleasant motivational state that postpones decisionmaking (Huang et al., 2018). The various risks associated with online shopping (e.g., financial risk, product risk, and time loss) (Demirgüneş, 2018) form a sense of hesitation toward online shopping, which leads to OSCA (Huang et al., 2018). While the impact of checkout hesitancy on OSCA has been welldocumented (Cho et al., 2006; Huang et al., 2018), earlier work has ignored the former's potential impact on purchasing from the offline channel (i.e., DBLR), especially due to the COVID19 pandemic. Therefore, this study extends the work of Huang et al. (2018) by exploring the sequential mediating effects of both hesitation at checkout and OSCA on the linkage between waiting for lower prices and DBLR.

Motivated by several reasons, this study also examines the moderating role of perceived transaction inconvenience. First, convenience is one of the most important predictors of a consumer's choice to shop online (Childers et al., 2001; Sembada and Koay, 2019). For example, a study by Tandon et al. (2016) highlighted that consumers' willingness to purchase online depends on the convenience of the website. Another study by Raman (2019) showed that the convenience of transactions is an important variable in forming consumers' positive attitudes and predicting their willingness to purchase online. Second, convenience makes an important contribution to the value of consumers' desired outcome (Sembada and Koay, 2019). Prior research has shown that when transactions become complex (e.g., lengthy registration forms, technical glitches, complex discount rules), consumers are more inclined to abandon their shopping carts due to the challenging buying process (Rajamma et al., 2009). In consideration of this evidence, another aim of this study is to explore the potential of perceived transaction inconvenience as the conditioning factor affecting hesitation to checkout.

The remainder of the study is organized as follows. First, the theoretical background is discussed and the relevant literature on price and the hesitation mindset is reviewed. Next, the research framework and hypotheses are developed, after which the process of data collection and the final sample size are described. Fourth, the results of the data analysis are presented. Then, the findings are discussed, based on which theoretical and practical implications are presented. Finally, the study's limitations are outlined and suggestions for future research are offered.

\section{THEORETICAL BACKGROUND AND HYPOTHESES}

\section{Stimulus-Organism-Response Model}

This study adopts the S-O-R framework as its overarching theory. As a widely used theory in the consumer behavior literature (Zheng et al., 2019; Akram et al., 2020; Arif et al., 2020; Paz and Delgado, 2020; Lim et al., 2021; Wang et al., 2022), this model emphasizes how environmental stimuli lead to cognitive and affective responses (i.e., perception, experience, 


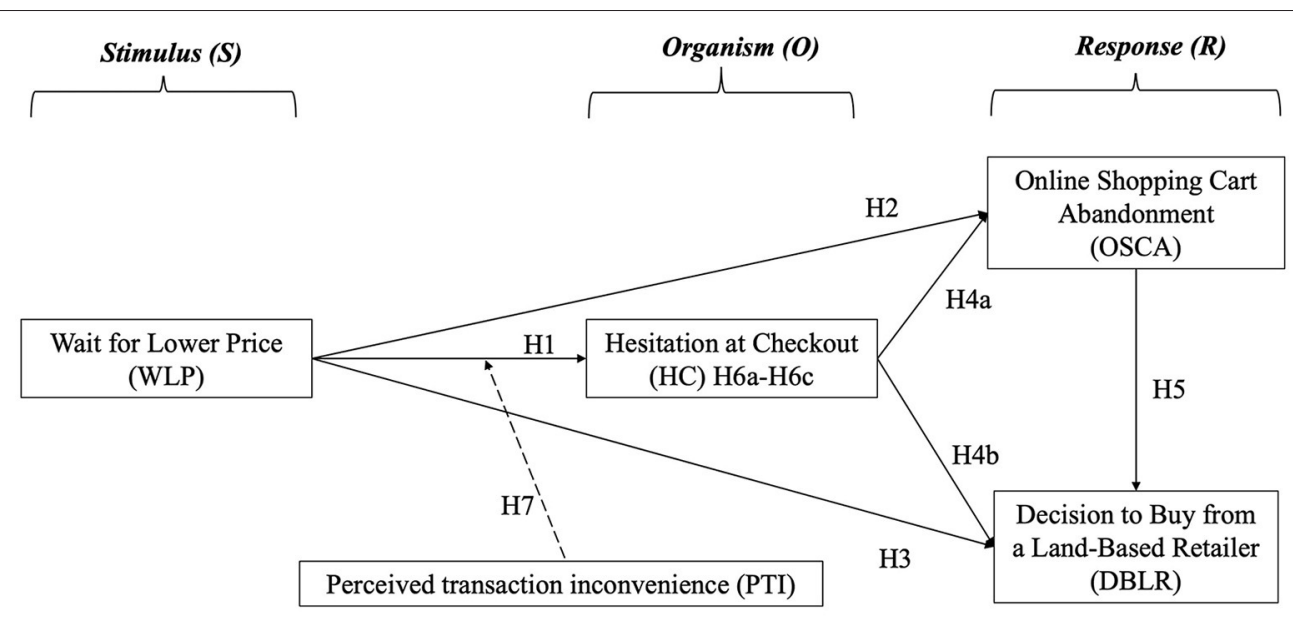

FIGURE 1 | Research model.

and evaluation), which in turn trigger certain psychological responses (i.e., attitudinal and behavioral responses) (Mehrabian and Russell, 1974).

In the domain of online selling, stimuli include websites, advertising, products, packaging, value, convenience, and entertainment (Hsu et al., 2012; Wong et al., 2012), all of which are known to influence consumers' emotions during the purchase journey (Jacoby, 2002). A great number of empirical studies anchored in the S-O-R model have confirmed that price is a significant stimulus that influences consumers' online and offline purchase behavior. For example, the study by Chen and Yao (2018) showed that consumers give positive feedback and tend to make impulse purchases when the price of a product is reduced. Furthermore, Cheah et al. (2020b) highlighted that price image has a huge impact on consumer perceptions, including perceived value, trust in retailers, and attitudes. More recently, research by Lee et al. (2021) identified that price attributes have a positive effect on perceived enjoyment as a predictor of consumer purchase behavior. Furthermore, the buyer behavior theory (Howard and Sheth, 1969) of price factor was extended to the online environment as an inhibitor, showing the impact of price on consumer shopping cart abandonment (Kukar-Kinney and Close, 2010). Thus, the empirical evidence strongly suggests that price is an important stimulus that affects consumer emotion and behavior.

Next, the "organism" is the undertaking of emotional, psychological, and cognitive internal processes between the stimulus and the response (Han and Kim, 2020). In the domain of marketing, factors such as satisfaction, emotion, and selfconfidence are considered as "organisms" that impact consumers' purchase intentions. For example, as recommended by Yuan et al. (2020), satisfaction can be used to measure the impact of consumer loyalty on mobile payment providers. Chang et al. (2011) study demonstrated that consumers with more positive emotional responses to retail environments and retailer are more likely to make impulse purchases. In addition, Cham et al. (2020) identified the positive impact of self-confidence on purchase decisions. Notably, Huang et al. (2018) measured the strong influence of checkout hesitation on OSCA behavior. That is, hesitation can be viewed as a decision-making style that appears in the process of exploring, alerting, and analyzing (Demirgüneş, 2018). Its impact is more significant before the consumer makes a final purchase decision (Peng and Chen, 2019). To further validate these early assumptions, this study echoes hesitation at checkout as the "organism" that impacts consumers' online purchase decisions, including OSCA and DBLR.

Taken together, our study enriches the existing literature by considering consumers' wait for lower prices as a stimulus that triggers their checkout hesitation "organism," while OSCA and DBLR are the target "responses" we seek to explore. To extend the applicability of the S-O-R model, we also incorporate perceived transaction inconvenience as a moderator that strengthens the magnitude of hesitation to checkout. The research model is shown in Figure 1. The hypothesized relationships between the proposed constructs are clarified in the following sections.

\section{Impacts of Consumers' Wait for Lower Price}

In online shopping, consumers are always eager to find the best deals, as price serves as an attractive stimulus in this environment (Kukar-Kinney and Close, 2010; Han et al., 2020). According to Kukar-Kinney and Close (2010), the wait for lower price concept is defined as "consumers' decision to wait until a lower price can be found on at least some item(s) in the cart, whether it be at the same or a different store, through the same or a different channel" (p. 244).

It has been some time since scholars reached the consensus that price awareness is a critical factor influencing consumer attitudes and behaviors (Zhang et al., 2020). Coppola and Sousa (2008) stated that price consciousness is the strongest predictor of overall shopping hesitancy. This claim is supported by Azimi, Milne and Miller (2020) finding that price consciousness increases the likelihood of procrastination and exit. This evidence seems to suggest that when consumers plan to wait for a sale 
or the lowest price, they are most likely to exhibit hesitation in buying (H1). Similarly, Nelson et al. (2007) demonstrated that the dynamics of price change prompt consumers to always check different stores or shop at different times. In addition, Kukar-Kinney and Close (2010) confirmed that waiting for lower prices is a key factor that increases the OSCA rate. Thus, this study hypothesizes that when consumers intend to wait for lower prices, the more likely they are to engage in OSCA (H2).

The outbreak of the COVID-19 pandemic has further led to a low level of consumer spending. Ellison et al. (2021) argued that many households are still facing financial deficiencies that may push them to switch to low-cost retailers. The studies by both Dahana et al. (2018) and Tu and Zhou (2012) confirm that consumers choose different purchase channels due to concerns about lower prices. In the case of an unexpected public health event, waiting for lower prices significantly increased the decision to buy from land-based retailers (H3). Therefore, supported by the S-O-R model, this study considers waiting for lower prices in online to be a significant stimulus that triggers hesitation at checkout as well as two different purchase decisions (i.e., OSCA and DBLR). The hypotheses are proposed as follows:

H1: The wait for lower prices positively affects hesitation at checkout.

$\mathrm{H} 2$ : The wait for lower prices positively affects OSCA.

H3: The wait for lower prices positively affects DBLR.

\section{Drivers of OSCA and DBLR}

Cho et al. (2006) defined hesitation at checkout as "postponing or deferring product purchases by having additional processing time before making final product-purchases on the Internet" (p. 261). Research by Jessup et al. (2009) clarified that the multiple choices or uncertainties present in online shopping can lead consumers to leave empty-handed. In particular, consumers terminate transactions most likely because they are hesitant (Huang et al., 2018). Likewise, Tian et al. (2019) concluded that consumers who have a "whether to buy" mindset have a greater willingness to abandon their purchase. These outcomes suggest that consumers who experience hesitation at checkout are more likely to engage in OSCA behavior $(\mathrm{H} 4 \mathrm{a})$. At the same time, hesitant consumers are more likely to purchase offline so as to mitigate the uncertainty risks associated with online purchases (e.g., product return risk, payment security risk, time loss) (Klepek and Bauerová, 2020). Therefore, we hypothesize that consumers with hesitation at checkout are more likely to turn toward DBLR (H4b).

Empirical evidence has confirmed that consumers choose different purchase channels to maximize their shopping benefits (Verhoef et al., 2015; Gensler et al., 2017). For instance, information overload in the searching stage is the main inhibitor of online shopping, driving consumers to switch toward offline purchases (Walsh and Mitchell, 2010) where they can see and touch what they want (Flavián et al., 2020). That is, consumers with a need for human interaction will move from online to offline shopping platforms as a way to mitigate the perceived uncertainty of online transactions (Aw, 2020). Additionally, brick-and-mortar stores save on delivery time by offering the immediate possession of items, which is an advantage often sought by consumers (Wollenburg et al., 2018). With this in mind, consumers are more likely to abandon their online shopping carts and show interest in land-based retailers to achieve their purchase needs (H5). Therefore, this study proposes the following hypotheses:

H4a: Hesitation at checkout positively affects OSCA. H4b: Hesitation at checkout positively affects DBLR. H5: OSCA positively affects DBLR.

\section{Mediation Effects}

The empirical evidence suggests that price influences consumers' purchase decisions (Büyükdag et al., 2020). Meanwhile, Cho et al. (2006) showed that checkout hesitation, due to key reasons like uncertainty, perceived risk, or additional information, affects consumer behavior. As a result, purchases are often delayed in the pursuit of lower prices and the search for merchants that offer a discount (Bauer et al., 2006). When checkout hesitation occurs, consumers are more likely to end their shopping process and leave the item(s) in the shopping cart (Huang et al., 2018). We therefore hypothesize that when consumers wait for lower prices, they may hesitate at checkout, leading to an increased likelihood of their DBLR (H6a). Based on this reasoning, we propose the following hypothesis:

H6a: Hesitation at checkout mediates the relationship between the wait for lower prices and DBLR.

Consumers perceive hesitation about their freedom of purchase choice when unexpected circumstances hinder their attitudinal or behavioral responses (Wong and Yeh, 2009). Hesitation is the most common problem in online purchasing because of the increased likelihood of consumers' exposure to risk (e.g., financial risk, product risk, and time loss) (Demirgüneş, 2018). In this context, it has been mentioned that consumers' feelings of hesitation that can lead to unpleasant motivational outcomes (Schrift et al., 2011). For example, consumers who hesitate at the checkout point are more likely to abandon their mobile shopping cart (Huang et al., 2018). We argue that shopping at a physical store can mitigate the risk of uncertainty that is inherent in online shopping. Therefore, consumers with checkout hesitancy are more likely to prefer on land-based retail shopping after abandoning their online shopping cart (H6b). We thus hypothesize that:

H6b: OSCA mediates the relationship between hesitation at checkout and DBLR.

From H6a and H6b, our study also suggests that hesitation at checkout and OSCA may play a sequential mediating role between the wait for lower prices and DBLR. Based on the S-O$\mathrm{R}$ model, when consumers choose to wait for lower prices, they are more likely to have checkout hesitation, which leads to both OSCA and DBLR behavior. Therefore, in this study, we take a step further by exploring hesitation at checkout and OSCA as sequential mechanisms that potentially connect the path between the wait for lower prices and DBLR (H6c). The hypothesis is proposed as: 
H6c: Hesitation at checkout and OSCA sequentially mediate the path between the wait for lower prices and DBLR.

\section{Moderating Effect of Perceived Transaction Inconvenience}

Convenience refers to "the extent to which a customer feels that the website is simple, intuitive, and user friendly" (Srinivasan et al., 2002, p. 44). Earlier e-commerce research has highlighted that when a transaction is accompanied by a bothersome process, it will lead to delay, switching, and even abandonment (Corsten and Gruen, 2003; Gunasti and Ross, 2009). Accordingly, a convenient website can accelerate online consumers' willingness to shop (Raman, 2019), whereas if consumers are hindered and frustrated during the transaction, they are less likely to return (Cameron, 1999).

Rajamma, Paswan and Hossain (2009) study extended the concept of convenience by proposing perceived transaction inconvenience (i.e., lengthy registration forms, technical glitches, etc.) as an important inhibiting factor that affects OSCA by complicating transactions and increasing consumers' frustration. Xu and Huang (2015) also highlighted that perceived transaction inconvenience (e.g., slow loading of web pages, complex transaction process, etc.) affects consumers' access to the shopping cart usage stage. Consumers who feel inconvenienced when accessing useful and direct information from a website would have a lower level of trust and subsequent willingness to visit online stores (Chen and Barnes, 2007). Indeed, it has been suggested that perceived transaction inconvenience decreases consumer trust in social media stores and exerts a significant impact on shopping intentions (Sembada and Koay, 2019). Based on this evidence, perceived transaction inconvenience would moderate the relationship between the wait for lower price and hesitation at checkout (H7). Therefore, we propose that:

H7: When perceived transaction inconvenience is high, the relationship between the wait for lower price and hesitation at checkout is stronger.

\section{METHODOLOGY}

\section{Data Collection and Sampling}

With over 872 million people engaging in online shopping, China has become the second-largest e-tailing market in the world after the United States (Statista, 2021a). However, many retailers still prefer to expand their brick-and-mortar stores, on the basis that the live experience attracts more consumers as a competitive advantage (Marian, 2021). Furthermore, a recent report by Statista (2021b) documented that as of December 2020 , despite $\sim 79.1 \%$ of Chinese consumers purchasing on various shopping platforms (e.g., Taobao, Tmall, and JD.COM), the OSCA rate was about $76.3 \%$ (Creditdonkey, 2019). One of the product categories with the highest OSCA rate is women's clothing (FinancesOnline, 2021). Evidently, empirical research on respondents with extensive Internet coverage and experience in online shopping is highly appropriate. Therefore, Mainland China was the study site for data collection in this study.
To collect the data, an online survey form was created through wenjuanxing (https://www.wjx.cn), one of the largest online survey platforms in China. The questionnaire was sampled using purposive sampling as this method is viewed effective in obtaining valid responses which could provide information relevant to the study (Saunders et al., 2012). In this study, respondents who are Chinese from Mainland China (Southern and Northern China) and have an online shopping experience are invited to answer the survey between January and March 2021. Since this study was targeted at online consumers in Mainland China, the questionnaire was designed in English and backtranslated into Chinese to ensure all the items expressed the same meaning (Brislin, 1970). Before formal data collection, the study instrument was pre-tested by a panel of five individuals, comprising practitioners, academics, and target respondents, to comment on the representativeness and applicability of the questionnaire. Afterwards, a pilot test was conducted with 30 respondents who fit the research context. Based on their feedback, the final measurement items underwent minor changes to their wording and layout (see Appendix 1).

After excluding one response with obvious regularity, a total of 883 valid responses were retained. According to Hair et al. (2019), a sample size of 883 is considered adequate; this number also exceeded the minimum sample size required for post-hoc analysis ${ }^{1}$. The demographic profile of the study participants was analyzed using frequency tests. The results showed that most of the respondents were aged between 21 and 30 years old (37.30\%), female $(58.60 \%)$, bachelor's degree holders $(55.30 \%)$, earned a monthly income of less than RMB 5,000 (75.80\%), and from the northern region (52.92\%). Additionally, a majority of the respondents indicated that they have 1-3 years of experience with online shopping (41.00\%) (see Table 1).

\section{Measures}

All items measured in this study were based on validated and reliable multi-item scales drawn from previous research, with some modifications to accommodate the current research setting. Wait for lower prices and OSCA were measured using the scales developed by Kukar-Kinney and Close (2010); hesitation at checkout was adapted from Cho, Kang and Cheon (2006) and Wong and Yeh (2009) scales; DBLR was measured using Rapp, Baker, Bachrach, Ogilvie and Beitelspacher (2015) scale; and finally, the scale for perceived transaction inconvenience was adapted from Rajamma et al. (2009). All these measurements have demonstrated great validity and reliability results, which is the reason for their inclusion in this study.

\section{DATA ANALYSIS}

Two types of statistical software were used to analyze the data in this study. First, the statistical software SPSS version 28 was used to assess demographic frequencies and check for common method bias (CMB). Subsequently, partial least squares-structural equation modeling (PLS-SEM) using

${ }^{1}$ With an effect size of 0.15 and a $95 \%$ power level, a minimum sample size of 160 responses was required for the present study (Fink, 2017; Memon et al., 2020). 
TABLE 1 | Respondent profile $(N=883)$.

\begin{tabular}{|c|c|c|c|}
\hline Demographic profile & Category & Frequency & Percent (\%) \\
\hline \multirow[t]{2}{*}{ Gender } & Male & 366 & 41.40 \\
\hline & Female & 517 & 58.60 \\
\hline \multirow[t]{5}{*}{ Age } & 20 years old and below & 327 & 37.00 \\
\hline & 21-30 years old & 329 & 37.30 \\
\hline & $31-40$ years old & 100 & 11.30 \\
\hline & $41-50$ years old & 78 & 8.80 \\
\hline & 51 years old and above & 49 & 5.50 \\
\hline \multirow[t]{8}{*}{ Monthly income } & Below 5,000 & 669 & 75.80 \\
\hline & $¥ 5,001-7,000$ & 90 & 10.20 \\
\hline & $¥ 7,001-9,000$ & 49 & 5.50 \\
\hline & $¥ 9,001-11,000$ & 38 & 4.30 \\
\hline & $¥ 11,001-13,000$ & 14 & 1.60 \\
\hline & $¥ 13,001-15,000$ & 7 & 0.80 \\
\hline & $¥ 15,001-17,000$ & 3 & 0.30 \\
\hline & $¥ 17,001$ and above & 13 & 1.50 \\
\hline \multirow[t]{6}{*}{ Education } & Less than High School & 34 & 3.90 \\
\hline & High School Diploma & 51 & 5.80 \\
\hline & College Degree & 196 & 22.20 \\
\hline & Bachelor's degree & 488 & 55.30 \\
\hline & Master's Degree & 99 & 11.20 \\
\hline & Doctorate (PhD or equivalent) & 15 & 1.70 \\
\hline \multirow[t]{2}{*}{ Residence } & Southern China & 416 & 47.10 \\
\hline & Northern China & 467 & 52.90 \\
\hline \multirow[t]{5}{*}{ Online Shopping Years } & Less than 1 year & 47 & 5.30 \\
\hline & $1-3$ years & 362 & 41.00 \\
\hline & $4-6$ years & 322 & 36.50 \\
\hline & $7-9$ years & 88 & 10.00 \\
\hline & 10 years or more & 64 & 7.20 \\
\hline
\end{tabular}

SmartPLS version 3.3.3 (Ringle et al., 2015; Sarstedt and Cheah, 2019) was employed to examine the hypothesized relationships. This technique has become a quasi-standard in the marketing field, especially when evaluating complex relationships between various latent variables (i.e., mediation and moderation) and simultaneously examining the relationships between variables in terms of explained variation (Hair, 2020). Additionally, PLSSEM is appropriate when the research goal is prediction-oriented and/or when the research is exploratory by nature (Cheah et al., 2019; Chin et al., 2020; Hwang et al., 2020).

\section{Common Method Bias}

Since the design of this study adopted a cross-sectional approach, two CMB assessments were performed: Harman's single factor (Podsakoff et al., 2003) and the full collinearity test (Kock and Lynn, 2012). First, the results of Harman's single factor test illustrated that the variance explained by the first factor was $36.036 \%(<40 \%)$, indicating that $\mathrm{CMB}$ was not a concern in this study (Babin et al., 2016). Second, the full collinearity test showed that the variance inflation factor (VIF) values were in the range of $1.247-2.038(<3.33)$ (refer to Table 2), signifying CMB does not pose any severe issue in this study (Kock and Lynn, 2012).

\section{Assessment of the Measurement Model}

Table 2 exhibits the reflective measurements' assessment in terms of their reliability and convergent validity. Regarding the outer loading, all items met the recommended outer loading criterion (i.e., between 0.572 and 0.887) (Hair et al., 2019). As for internal reliability, all metrics (CA, rho_A, and CR) demonstrated values above the critical value of 0.7 ; thus, all the measurements were internally consistent (Hair et al., 2019). In terms of the AVE, all the constructs reported values above 0.5 (Hair et al., 2019), establishing their convergent validity.

In addition, we assessed discriminant validity using the heterotrait-monotrait ratio of correlations (HTMT). Based on Table 3, all the HTMT values were lower than the conservative threshold value of 0.85 (Henseler et al., 2015). Thus, it can be concluded that discriminant validity was established between all the constructs.

\section{Assessment of the Structural Model}

The assessment of the structural model started by evaluating the collinearity between the predictors. Table 4 exhibits that the VIF values of all the combination paths-which ranged from 1.144 to 2.052-were below the threshold of 3.33 (Becker et al., 2015). Hence, collinearity between the predictors was not an issue in this dataset.

Based on Table 4, wait for lower prices revealed a positive relationship with hesitation at checkout $(\beta=0.326$; $p<0.000)$, supporting $\mathrm{H} 1$. The effects of the wait for lower prices on OSCA $(\beta=0.098 ; p<0.000)$ and $\operatorname{DBLR}(\beta=0.136 ; p<0.000)$ were also found to be positive and significant; hence, both $\mathrm{H} 2$ and H3 were supported. Similarly, hesitation at checkout positively impacted both OSCA $(\beta=0.654 ; p<0.000)$ and DBLR $(\beta=$ $0.090 ; p<0.05)$ in this study, supporting H4a and H4b. Finally, OSCA $(\beta=0.350 ; p<0.000)$ showed a positive impact on DBLR, confirming $\mathrm{H} 5$.

From these findings, the $\mathrm{R}^{2}$ results from $\mathrm{H} 1, \mathrm{H} 2$, and $\mathrm{H} 3$ were $\sim 23.7,49.1$, and $24.0 \%$, respectively. To assess the significance of each path, the findings of effect size $\left(f^{2}\right)$ were also reported. Based on Table 4, the hypothesized paths of H1, H3, and H5 carried a small $\left(f^{2}\right.$ ranged from 0.021 to 0.123$)$ but meaningful effect (Cohen, 1988). For the hypothesized path H4a, the results showed a large effect size $\left(f^{2}=0.697\right)$, while the paths of $\mathrm{H} 2$ and $\mathrm{H} 4 \mathrm{~b}$ exhibited a trivial effect size with values $<0.02$.

Finally, the predictive relevance of the model was evaluated using the blindfolding procedure (Shmueli et al., 2019). The $Q^{2}$ values for all endogenous constructs in Table 4 were greater than zero, verifying the model's predictive relevance.

\section{Mediating Analysis}

To account for the mediation roles of hesitation at checkout and OSCA, we used the method of Aguinis et al. (2017) and Nitzl et al. (2016). As can be seen in Table 4, the proposed mediation effects of OSCA (H6b) $(\beta=0.230 ; p<0.000)$ and the sequential mediation (H6c) $(\beta=0.074 ; p<0.000)$ exhibited a significant 
TABLE 2 | Results of the measurement model.

\begin{tabular}{|c|c|c|c|c|c|c|c|}
\hline Construct & Item & Loading & VIF & CA & rho_A & CR & AVE \\
\hline \multirow[t]{3}{*}{ Wait for lower prices } & WLP1 & 0.858 & 1.229 & 0.604 & 0.643 & 0.793 & 0.568 \\
\hline & WLP2 & 0.801 & & & & & \\
\hline & WLP3 & 0.572 & & & & & \\
\hline \multirow[t]{5}{*}{ Hesitation at checkout } & $\mathrm{HC} 1$ & 0.816 & 2.054 & 0.913 & 0.914 & 0.935 & 0.742 \\
\hline & $\mathrm{HC} 2$ & 0.849 & & & & & \\
\hline & HC3 & 0.887 & & & & & \\
\hline & HC4 & 0.878 & & & & & \\
\hline & HC5 & 0.876 & & & & & \\
\hline \multirow{4}{*}{$\begin{array}{l}\text { Online shopping cart } \\
\text { abandonment }\end{array}$} & OSCA1 & 0.828 & 1.968 & 0.813 & 0.819 & 0.878 & 0.645 \\
\hline & OSCA2 & 0.861 & & & & & \\
\hline & OSCA3 & 0.822 & & & & & \\
\hline & OSCA4 & 0.690 & & & & & \\
\hline \multirow{4}{*}{$\begin{array}{l}\text { Decision to buy from a } \\
\text { land-based retailer }\end{array}$} & DBLR1 & 0.831 & 1.573 & 0.859 & 0.876 & 0.903 & 0.699 \\
\hline & DBLR2 & 0.866 & & & & & \\
\hline & DBLR3 & 0.850 & & & & & \\
\hline & DBLR4 & 0.796 & & & & & \\
\hline \multirow{4}{*}{$\begin{array}{l}\text { Perceived transaction } \\
\text { inconvenience }\end{array}$} & PTI1 & 0.661 & 1.142 & 0.712 & 0.718 & 0.822 & 0.537 \\
\hline & PTI2 & 0.720 & & & & & \\
\hline & РTI3 & 0.809 & & & & & \\
\hline & PTI4 & 0.734 & & & & & \\
\hline
\end{tabular}

VIF, variance inflation factor; $C A$, convergent validity; $C R$, composite reliability; AVE, average variance extract.

TABLE 3 | Discriminant validity test using HTMT criterion.

\begin{tabular}{|c|c|c|c|c|c|}
\hline Construct & 1 & 2 & 3 & 4 & 5 \\
\hline \multicolumn{6}{|c|}{ 1. Decision to buy from a land-based retailer } \\
\hline 2. Hesitation at checkout & 0.420 & & & & \\
\hline 3. Perceived transaction inconvenience & 0.480 & 0.430 & & & \\
\hline 4. Online shopping cart abandonment & 0.543 & 0.803 & 0.457 & & \\
\hline 5. Wait for lower prices & 0.439 & 0.545 & 0.555 & 0.518 & \\
\hline
\end{tabular}

HTMT <0.85 (Henseler et al., 2015).

indirect effect with full mediation, while hesitation at checkout (H6a) failed to show significant mediation.

\section{Moderating Analysis}

Finally, a two-stage approach was used for the moderation analysis (Becker et al., 2018). As shown in Table 4, perceived transaction inconvenience was found to moderate the relationship between the wait for lower prices and hesitation at checkout ( $\beta=0.101, p<0.05$ ); thus, H7 was supported. To corroborate these findings, we also assessed both the effect and the interaction plot (Dawson, 2014). The results reported that H7 had a small effect $\left(f^{2}=0.021\right)$ (see Table 4). The interaction plot, on the other hand, indicated that the line of high perceived transaction inconvenience has a steeper gradient than low perceived transaction inconvenience (see Figure 2). This indicates that when consumers perceive high transaction inconvenience during online shopping, the positive relationship between the wait for lower prices and hesitation at checkout is stronger.

\section{DISCUSSION}

\section{Findings}

This study aimed to explore the antecedents that impact OSCA and DBLR among online consumers in Mainland China. Our findings exhibit that waiting for lower prices affects consumers' internal cognitive process (i.e., hesitation at checkout), which in turn influences their purchase decision (i.e., OSCA, DBLR). Perceived transaction inconvenience is evidenced as a conditional effect that reinforces consumers' OSCA behavior. This study provides empirical support for these findings with a strong foundation anchored in our framework constructed using the S-O-R model.

First, we found that the wait for lower prices positively influences hesitation at checkout, OSCA, and DBLR (H1, H2, and $\mathrm{H} 3$ were supported). This finding suggests that price incentives substantially interfere with consumers' cognitive state and purchase decisions in online shopping. Confirming previous research, prices listed on online stores influence consumers' decisions, whereby those with high value consciousness are more 
TABLE 4 | Structural model results.

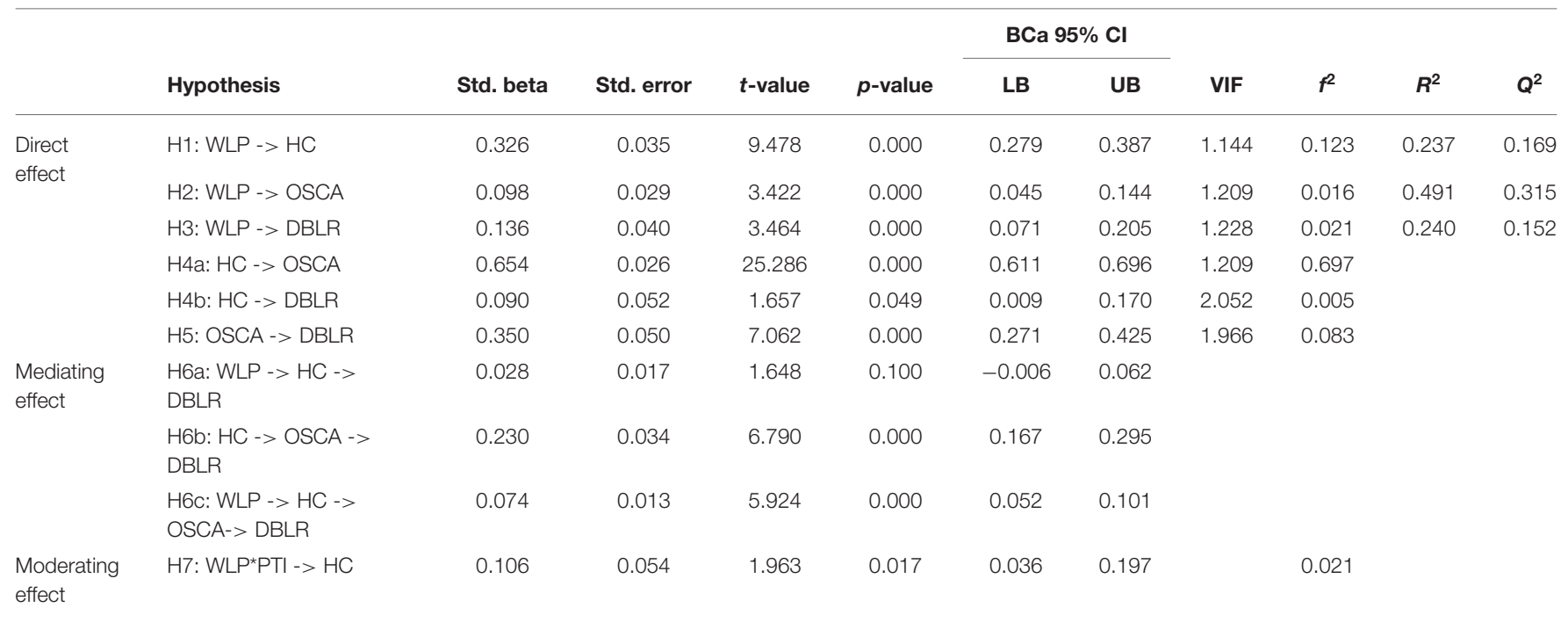

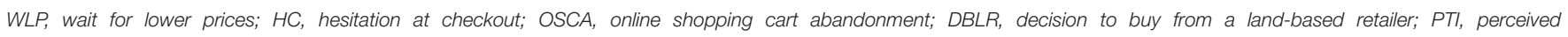
transaction inconvenience.

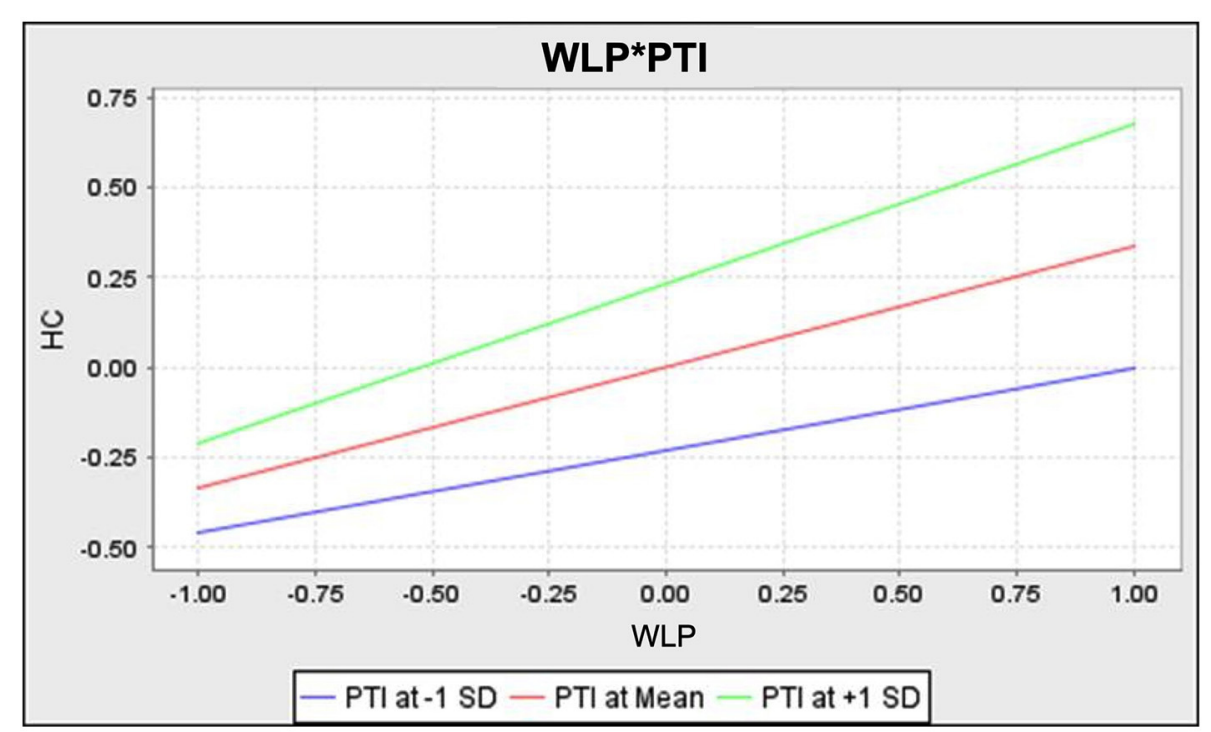

FIGURE 2 | Interaction plot of WLP*PTI on hesitation at checkout.

likely to delay online purchases (Cho et al., 2006) and eventually choose to select items in physical stores (Kukar-Kinney and Close, 2010).

In addition, hesitation at checkout has the greatest impact on consumers' abandonment of their online shopping carts (H4a was supported). This finding confirms Huang, Korfiatis and Chang (2018) postulation that consumers who hesitate at checkout are more likely to abandon their shopping carts. Meanwhile, we extended the study by Huang et al. (2018) to highlight the relationship between hesitation at checkout and the decision to buy from a land-based retailer. The results of the study suggest that hesitation at checkout has a positive direct impact on DBLR (H4b was supported). Suggesting that most online consumers in Mainland China prefer to visit brick-andmortar stores in the post-pandemic period as they have the chance to physically touch and feel items before committing to a purchase. In addition, this supports the earlier findings of KukarKinney and Close (2010) that consumers choose physical stores after abandoning their online shopping carts (H5 is supported), which demonstrates that consumers who abandon their cart are very likely to re-pick similar items from physical outlets to reduce worries and risks from online purchasing.

Next, the existing literature highlights those consumers are readily abandoning their shopping carts because they are 
value-conscious (Mishra et al., 2021). Meanwhile, hesitant consumers are more likely to end their shopping process and leave the item in their online shopping cart (Huang et al., 2018). This study used hesitation at checkout and OSCA as sequential mediators to assess the effect between the wait for lower prices and DBLR. The results show that two indirect effect hypotheses were supported (H6b, H6c), while H6a was not. This finding supports the study of Kukar-Kinney and Close (2010) that extends the roles of hesitation at checkout and OSCA as mediating variables that explain the overall proposed S-O$\mathrm{R}$ model.

Finally, the findings show that perceived transaction inconvenience is a moderator that strengthens the relationship between the wait for lower prices and hesitation at checkout $(\mathrm{H} 7$ was supported), due to the fact that consumers' high perceived transaction inconvenience creates expectation uncertainty (Harrison-Walker, 2002; Rajamma et al., 2009). Thus, our results extend previous arguments in the literature and consolidate our understanding of how perceived transaction inconvenience leads to OSCA behavior (Rajamma et al., 2009).

\section{Theoretical Implications}

The results of the study provide numerous theoretical contributions. First, the present study enriches the applicability of the S-O-R model in OSCA research. Specifically, it adds to the literature on consumer purchase decisions by investigating the wait for lower prices as a stimulus. A large number of scholars have confirmed that price affects consumers' purchase intention (Coppola and Sousa, 2008; Azimi et al., 2020; Zhang et al., 2020) across different selling platforms. However, there have been no in-depth studies on how price factors affect OSCA and DBLR, especially after the outbreak of COVID-19. In this study, we found that waiting for lower prices is an important antecedent of consumers' choices pertaining to hesitation at checkout, OSCA, and DBLR. This finding echo that of Kukar-Kinney and Close (2010), highlighting the important role of price factors in consumer purchase decisions. Next, this study establishes hesitation at checkout as an "organism" that produces different responses (i.e., OSCA and DBLR) under the influence of stimuli. Extending the study of Huang et al. (2018), we enhance the value of hesitation at checkout in existing research with support from the S-O-R model.

Second, this study moves beyond direct relationships to examine hesitation at checkout and OSCA as sequential mediators that elucidate the linkage between the wait for lower prices and DBLR. The findings support our proposed hypotheses that consumers delay their purchase behaviors due to concerns about seeking lower prices, which leads to OSCA and eventually, their decision to buy the selected items from a physical store. This sequential mediation path does not only complement the conclusions drawn in the study of KukarKinney and Close (2010) but also offers a comprehensive understanding for marketing researchers, particularly in the OSCA and DBLR literature.

Finally, based on the present results, perceived transaction inconvenience can be integrated as a boundary condition in addressing the OSCA issue. The moderation analysis shows that when consumers perceive higher transaction inconvenience, the positive relationship between the wait for lower prices and checkout hesitation becomes stronger. It can subsequently be concluded that the likelihood of consumers' abandoning their online shopping cart is high when transaction inconvenience arises. This outlines an important concern for future research which intends to understand the factors that influence hesitation to checkout and OSCA.

\section{Practical Implications}

Our findings also provide meaningful implications to reduce the OSCA phenomenon. First, the significant impact of the wait for lower prices on hesitation at checkout, OSCA, and DBLR suggests that price is a key factor in consumers' decision to buy from either online or offline stores. Consumers tend to wait for items to be discounted or go to different online stores to compare prices. Ultimately, they may even choose a physical store for price-related reasons, such as to avoid shipping fees. Therefore, eretailers should take effective measures to bridge the gap between pricing and OSCA. Hidden price promotions can be one of the strategics to address the issues, where final prices are not revealed to consumers when they first encounter a product ( $\mathrm{Li}$ et al., 2022). Through this strategy, customers viewing the product page will focus their attention on the product's information, features, and benefits, rather than just its price (Hoang, 2020). Indeed, improving customer experience in this manner can help motivate visits and increase the likelihood of potential consumers adding the product to their shopping cart. In addition, by offering higher discounts, e-retailers can increase their prospects of meeting or exceeding consumers' expectations of price. Apart from that, e-retailers should also consider implementing a daily low-price strategy and flash sales at different periods as a way to boost online sales. More importantly, our study accounts for consumers' DBLR behavior by urging e-retailers to offer real financial compensation in their offline stores in the form of coupons, cashback, free samples, and more. This is beneficial for consumers who tend to go to brick-and-mortar stores.

Second, by observing checkout hesitation's significant impact on consumers' purchase decisions, e-retailers should develop strategies to reduce such feelings of hesitation. For example, it is important to provide more details on product descriptions and enhance search engine optimization on product pages to eliminate the feeling of hesitation. Next, e-retailers should hire experienced sellers to answer consumer inquiries and improve timely responses during the online shopping process. In addition, they can consider offering "warm" strategies (i.e., first-person narration, "I" or "you") for consumers to provide 24/7 support services and increase interaction with consumers (e.g., using chatbots, voice recognition, and live streaming video) (Lim et al., 2021). This measure could help consumers move quickly to the payment stage, which would ultimately reduce OSCA issues. For consumers who prefer brick-and-mortar stores, retailers can implement offline smart retailing in their physical stores. For example, through digital transformation (e.g., electronic price tags) and intelligent empowerment (e.g., robot guidance), physical stores can become more intelligent and firmly "stick" consumers offline. 
Finally, this study unearths new evidence on perceived transaction inconvenience, signifying an important idea in reducing the OSCA phenomenon. Often, transaction inconvenience in online shopping is mainly due to the lack of flexibility, such as the need to fill out lengthy registration information forms (Rajamma et al., 2009). E-retailers should be sympathetic to the needs of consumers and reduce these negative reactions by providing basic information storage features, online self-service options, and easier initiation of transaction processes. E-retailers can also intervene to build trust through the introduction of external links. For example, they can insert links to partner platforms (e.g., Whatsapp, WeChat) on their sales site to establish positive partnerships, such as by regularly interacting with consumers, sending item shipment progress details, or promoting the goodwill of their transactions. When consumers are aware of the controllability of an operation, their perceived transaction inconvenience will weaken. E-retailers should thus strive to capture behavioral cues from consumers to ensure that the latter are gently pushed down the sales funnel to conversion.

\section{Conclusion, Limitations and Future Research}

Based on the S-O-R model, this study examined the factors that influence OSCA behavior and DBLR among Mainland Chinese consumers. Three notable findings were revealed, including (i) the positive effect between the wait for lower prices and hesitation at checkout; (ii) the sequential mediation effects of hesitation at checkout and OSCA; and (iii) perceived transaction inconvenience as a non-negligible boundary condition that strengthens the relationship between the wait for lower prices and hesitation at checkout.

Although this study provided several theoretical and practical implications, some limitations could not be avoided. First, we used a cross-sectional questionnaire to capture respondents' online shopping experience in Mainland China. Future research could incorporate an experimental design to better assess consumers' OSCA behavioral response. For example, by building realistic shopping environments where respondents operate the online shopping process in their natural state, scholars can assess inhibitors of OSCA that arise at any time by monitoring respondents' clickstream data or face-to-face communication (Rubin et al., 2020). Using experimental scenarios also allows the observation of differential responses by segmenting based on time (Li et al., 2021), product categories (Zhao et al., 2021), and selling platforms (Jiang et al., 2021), which would tap into more valuable information. In addition, future researcher can

\section{REFERENCES}

Aguinis, H., Edwards, J. R., and Bradley, K. J. (2017). Improving our understanding of moderation and mediation in strategic management research. Organ. Res. Methods 20, 665-685. doi: 10.1177/1094428115627498

Akram, U., Ansari, A. R., Fu, G., and Junaid, M. (2020). Feeling hungry? Let's order through mobile! Examining the fast-food mobile commerce in China. J. Retail. Consum. Serv. 56:102142. doi: 10.1016/j.jretconser.2020.102142 used experimental design to compared the different generations (Generation X, Generation Y, and Generation Z) toward the perception of OSCA and how it could have different behavioral outcomes on OSCA and intention to visit brick-and-mortar retail stores.

Second, retailers can use emerging technologies such as artificial intelligence to gain strategic momentum. For example, applying $3 \mathrm{D}$ gestures and service robotics to provide consumers with contactless smart services. This is because the actual use of contactless smart services like robots can positively affect the consumer experience (Guan et al., 2021). Therefore, when analyzing the OSCA phenomenon and intentions to visit brickand-mortar retail stores, future research could analyze the importance of using technology as antecedents. The extension of capturing the complete consumers' behavioral decision through factors such as technology self-efficacy, warmth, and anthropomorphism will be interesting for future research.

Next, perceived transaction inconvenience was the only moderator used to explain hesitation to checkout. Therefore, we encourage future scholars to look into other potential moderating effects that may mitigate the relationship between the wait for lower prices and hesitation at checkout. For example, recent research by Cheah et al. (2020a) highlights that trust is an important factor to reduce the perceived complexity associated with online purchasing activities (BoŽič et al., 2020).

Finally, we also suggest for scholars to expand the current research model in other developing countries (e.g., Malaysia, Brazil) or in a cross-country scale to determine the purchasing behavior of online consumers in different cultural contexts.

\section{DATA AVAILABILITY STATEMENT}

The raw data supporting the conclusions of this article will be made available by the authors, without undue reservation.

\section{AUTHOR CONTRIBUTIONS}

SW, J-HC, and X-JL contributed to conception and design of the study. SW organized the database. J-HC performed the statistical analysis. SW wrote the first draft of the manuscript. YY, BN, X-JL, and J-HC wrote sections of the manuscript. All authors contributed to manuscript revision, read, and approved the submitted version.

\section{FUNDING}

Shaoguan University cultivates researcher funding.
Arif, I., Aslam, W., and Siddiqui, H. (2020). Influence of brand related user-generated content through Facebook on consumer behaviour: a stimulus-organism-response framework. Int. J. Electronic Business 15, 109-132. doi: 10.1504/IJEB.2020. 106502

Aw, E. C. X. (2020). Understanding consumers' paths to webrooming: a complexity approach. J. Retail. Consumer Serv. 53:101991. doi: 10.1016/j.jretconser.2019.101991 
Azimi, S., Milne, G. R., and Miller, E. G. (2020). Why do consumers procrastinate and what happens next? J. Consumer Market. 37, 795-805. doi: 10.1108/JCM-07-2019-3329

Babin, B. J., Griffin, M., and Hair Jr, J. F. (2016). Heresies and sacred cows in scholarly marketing publications. J. Bus. Res. 69, 3133-3138. doi: 10.1016/j.jbusres.2015.12.001

Bauer, H. H., Falk, T., and Hammerschmidt, M. (2006). eTransQual: a transaction process-based approach for capturing service quality in online shopping. J. Bus. Res. 59, 866-875. doi: 10.1016/j.jbusres.2006.01.021

Becker, J. M., Ringle, C. M., and Sarstedt, M. (2018). Estimating moderating effects in PLS-SEM and PLSc-SEM: interaction term generation* data treatment. J. Appl. Struct. Equation Model. 2, 1-21. doi: 10.47263/JASEM.2(2)01

Becker, J. M., Ringle, C. M., Sarstedt, M., and Völckner, F. (2015). How collinearity affects mixture regression results. Mark. Lett. 26, 643-659. doi: 10.1007/s11002-014-9299-9

Božič, B., Siebert, S., and Martin, G. (2020). A grounded theory study of factors and conditions associated with customer trust recovery in a retailer. J. Bus. Res. 109, 440-448. doi: 10.1016/j.jbusres.2019.12.032

Brislin, R. W. (1970). Back-translation for cross-cultural research. J. Cross Cult. Psychol. 1, 185-216. doi: 10.1177/135910457000100301

Büyükdag, N., Soysal, A. N., and Kitapci, O. (2020). The effect of specific discount pattern in terms of price promotions on perceived price attractiveness and purchase intention: an experimental research. J. Retail. Consumer Serv. 55:102112. doi: 10.1016/j.jretconser.2020.102112

Cameron, M. (1999). Content that works on the web. Target Market. 1, 22-58.

Chad, B. (2021). Shoppers Still Prefer In-Store Over Online Shopping. Available online at: https://www.businessnewsdaily.com/7756-online-shoppingpreferences.html (accessed November 03, 2021).

Cham, T. H., Cheng, B. L., and Ng, C. K. Y. (2020). Cruising down millennials' fashion runway: a cross-functional study beyond Pacific borders. Young Consumers 22, 28-67. doi: 10.1108/YC-05-2020-1140

Chang, H. J., Eckman, M., and Yan, R. N. (2011). Application of the stimulusorganism-response model to the retail environment: the role of hedonic motivation in impulse buying behavior. Int. Rev. Retail Distribut. Consumer Res. 21, 233-249. doi: 10.1080/09593969.2011.578798

Cheah, J. H., Lim, X. J., Ting, H., Liu, Y., and Quach, S. (2020a). Are privacy concerns still relevant? Revisiting consumer behaviour in omnichannel retailing. J. Retail. Consumer Serv. 102242. doi: 10.1016/j.jretconser.2020.102242

Cheah, J. H., Ting, H., Ramayah, T., Memon, M. A., Cham, T. H., and Ciavolino, E. (2019). A comparison of five reflective-formative estimation approaches: reconsideration and recommendations for tourism research. Qual. Quantity 53, 1421-1458. doi: 10.1007/s11135-018-0821-7

Cheah, J. H., Waller, D., Thaichon, P., Ting, H., and Lim, X. J. (2020b). Price image and the sugrophobia effect on luxury retail purchase intention. J. Retail. Consumer Serv. 57:102188. doi: 10.1016/j.jretconser.2020.102188

Chen, C. C., and Yao, J. Y. (2018). What drives impulse buying behaviors in a mobile auction? The perspective of the Stimulus-Organism-Response model. Telematics Informatics 35, 1249-1262. doi: 10.1016/j.tele.2018.02.007

Chen, Y. H., and Barnes, S. (2007). Initial trust and online buyer behaviour. Indus. Manage. Data Syst. 107, 21-36. doi: 10.1108/02635570710719034

Childers, T. L., Carr, C. L., Peck, J., and Carson, S. (2001). Hedonic and utilitarian motivations for online retail shopping behavior. J. Retail. 77, 511-535. doi: 10.1016/S0022-4359(01)00056-2

Chin, W., Cheah, J. H., Liu, Y., Ting, H., Lim, X. J., and Cham, T. H. (2020). Demystifying the role of causal-predictive modeling using partial least squares structural equation modeling in information systems research. Indus. Manage. Data Syst. 120, 2161-2209. doi: 10.1108/IMDS-10-2019-0529

Cho, C. H., Kang, J., and Cheon, H. J. (2006). Online shopping hesitation. CyberPsychol. Behav. 9, 261-274. doi: 10.1089/cpb.2006.9.261

Cohen, J. (1988). Statistical Power Analysis for the Behavioral Sciences. Hillsdale, NJ: Erlbaum.

Coppola, J., and Sousa, K. (2008). "Characteristics affecting the abandonment of ecommerce shopping carts-a pilot study," in Northeast Decision Sciences Institute Proceedings, (Baltimore) 384-389.

Corsten, D., and Gruen, T. (2003). Desperately seeking shelf availability: an examination of the extent, the causes, and the efforts to address retail out-of-stocks. Int. J. Retail Distribution Manage. 31, 605-617. doi: 10.1108/09590550310507731

Creditdonkey. (2019). Shopping Cart Abandonment Statistics. Available online at: https://www.creditdonkey.com/shopping-abandonment-statistics.html (accessed November 04, 2021).

Dahana, W. D., Shin, H., and Katsumata, S. (2018). Influence of individual characteristics on whether and how much consumers engage in showrooming behavior. Electronic Commerce Res. 18, 665-692. doi: 10.1007/s10660-017-9277-4

Dawson, J. F. (2014). Moderation in management research: what, why, when, and how. J. Bus. Psychol. 29, 1-19. doi: 10.1007/s10869-013-9308-7

Daxue (2021). Payment Methods in China: How China Became a Mobile-First Nation. Available online at: https://daxueconsulting.com/payment-methodsin-china/ (accessed December 21, 2021).

Demirgüneş, K. B. (2018). "Determination of factors that cause shopping hesitation," in The 2nd International Conference on the Changing World and Social Research (Barcelona), 23-25.

Elkind, J. (2020). Shoppers Are Abandoning Their Online Carts More Than Ever-Here's Why. Available online at: https://www.today.com/style/onlinebrowsing-new-window-shopping-t182491 (accessed November 02, 2021).

Ellison, B., McFadden, B., Rickard, B. J., and Wilson, N. L. (2021). Examining food purchase behavior and food values during the COVID-19 pandemic. Appl. Econ. Perspect. Policy 43, 58-72. doi: 10.1002/aepp.13118

FinancesOnline (2021). 88 Relevant Shopping Cart Abandonment Statistics: 2020/2021 Value, Causes, Analysis \& Data. Available online at: https:// financesonline.com/shopping-cart-abandonment-statistics/ (accessed November 02, 2021).

Fink, A. (2017). How to Conduct Surveys: A Step-by-Step Guide, 6th Edn. Thousand Oaks, CA: Sage.

Flavián, C., Gurrea, R., and Orus, C. (2020). Combining channels to make smart purchases: the role of webrooming and showrooming. J. Retail. Consumer Serv. 52:101923. doi: 10.1016/j.jretconser.2019.101923

Garaus, M. (2018). Confusion in internet retailing: causes and consequences. Internet Res. 28, 477-499. doi: 10.1108/IntR-11-2016-0356

Gensler, S., Neslin, S. A., and Verhoef, P. C. (2017). The showrooming phenomenon: it's more than just about price. J. Interactive Market. 38, 29-43. doi: 10.1016/j.intmar.2017.01.003

Guan, X., Gong, J., Li, M., and Huan, T. C. (2021). Exploring key factors influencing customer behavioral intention in robot restaurants. Int. J. Contemporary Hospitality Manage. [Epub ahead of print]. doi: 10.1108/IJCHM-06-2021-0807

Gunasti, K., and Ross, W. T. (2009). How inferences about missing attributes decrease the tendency to defer choice and increase purchase probability. J. Consumer Res. 35, 823-837. doi: 10.1086/5 93684

Hair, J. F., Black, W. C., Babin, B. J., Anderson, R. E., and Tatham, R. L. (2019). Multivariate Data Analysis, 8th Edn. Cengage, Hampshire, U.K.

Hair, J. F. Jr. (2020). Next-generation prediction metrics for composite-based PLSSEM. Indus. Manage. Data Syst. 121, 5-11. doi: 10.1108/IMDS-08-2020-0505

Han, H., Al-Ansi, A., Chi, X., Baek, H., and Lee, K. S. (2020). Impact of environmental CSR, service quality, emotional attachment, and price perception on word-of-mouth for full-service airlines. Sustainability 12:3974. doi: $10.3390 /$ su12103974

Han, S. L., and Kim, K. (2020). Role of consumption values in the luxury brand experience: moderating effects of category and the generation gap. J. Retail. Consumer Serv. 57:102249. doi: 10.1016/j.jretconser.2020.102249

Harrison-Walker, L. J. (2002). If you build it, will they come? Barriers to international e-marketing. J. Market. Theory Prac. 10, 12-21. doi: 10.1080/10696679.2002.11501912

Henseler, J., Ringle, C. M., and Sarstedt, M. (2015). A new criterion for assessing discriminant validity in variance-based structural equation modeling. J. Acad. Market. Sci. 43, 115-135. doi: 10.1007/s11747-014-0403-8

Hoang (2020). Hide Price in ECommerce: Should or Shouldn't? B2B Or B2C? Available online at: https://bsscommerce.com/blog/hide-price-ecommerce/ (accessed November 22, 2021).

Howard, J. A., and Sheth, J. N. (1969). The Theory of Buyer Behavior. New York, NY: John Wiley and Sons. 
Hsu, C. L., Chang, K. C., and Chen, M. C. (2012). The impact of website quality on customer satisfaction and purchase intention: perceived playfulness and perceived flow as mediators. Information Syst. e-Business Manage. 10, 549-570. doi: 10.1007/s10257-011-0181-5

Huang, G. H., Korfiatis, N., and Chang, C. T. (2018). Mobile shopping cart abandonment: the roles of conflicts, ambivalence, and hesitation. J. Bus. Res. 85, 165-174. doi: 10.1016/j.jbusres.2017.12.008

Hwang, H., Sarstedt, M., Cheah, J. H., and Ringle, C. M. (2020). A concept analysis of methodological research on composite-based structural equation modeling: bridging PLSPM and GSCA. Behaviormetrika 47, 219-241. doi: 10.1007/s41237-019-00085-5

Inmar, I. (2020). Steve Ustaris, vp Marketing, Retail Cloud Data and Media Solutions. Available online at: https://www.inmar.com/blog/thoughtleadership/covid19/online-shopping-behavior-march-what-can-we-learnabout-consumer-mindsets (accessed November 02, 2021).

Jacoby, J. (2002). Stimulus-organism-response reconsidered: an evolutionary step in modeling (consumer) behavior. J. Consumer Psychol. 12, 51-57. doi: 10.1207/S15327663JCP1201_05

Jessup, R. K., Veinott, E. S., Todd, P. M., and Busemeyer, J. R. (2009). Leaving the store empty-handed: testing explanations for the too-much-choice effect using decision field theory. Psychol. Market. 26, 299-320. doi: 10.1002/mar.20274

Jiang, D., Zhang, G., and Wang, L. (2021). Empty the shopping cart? The effect of shopping cart item sorting on online shopping cart abandonment behavior. J. Theor. Appl. Electronic Commerce Res. 16, 1973-1996. doi: 10.3390/jtaer16060111

Jin, S., Balliet, D., Romano, A., Spadaro, G., Van Lissa, C. J., Agostini, M., et al. (2021). Intergenerational conflicts of interest and prosocial behavior during the COVID-19 pandemic. Pers. Individ. Dif. 171:110535. doi: $10.1016 /$ j.paid.2020.110535

Kapoor, A. P., and Vij, M. (2021). Following you wherever you go: mobile shopping 'cart-checkout'abandonment. J. Retail. Consumer Serv. 61:102553. doi: 10.1016/j.jretconser.2021.102553

Klepek, M., and Bauerová, R. (2020). Why do retail customers hesitate for shopping grocery online? Technol. Econ. Dev. Econ. 26, 1444-1462. doi: $10.3846 /$ tede. 2020.13970

Kock, N., and Lynn, G. (2012). Lateral collinearity and misleading results in variance-based SEM: an illustration and recommendations. J. Assoc. Information Syst. 13, 546-580. doi: 10.17705/1jais. 00302

Kukar-Kinney, M., and Close, A. G. (2010). The determinants of consumers' online shopping cart abandonment. J. Acad. Market. Sci. 38, 240-250. doi: 10.1007/s11747-009-0141-5

Lee, C. H., Chen, C. W. D., Huang, S. F., Chang, Y. T., and Demirci, S. (2021). Exploring consumers' impulse buying behavior on online apparel websites: an empirical investigation on consumer perceptions. Int. J. Electronic Commerce Stud. 12, 119-142. doi: 10.7903/ijecs.1971

Li, J., Luo, X., Lu, X., and Moriguchi, T. (2021). The double-edged effects of ecommerce cart retargeting: does retargeting too early backfire? J. Mark. 85, 123-140. doi: 10.1177/0022242920959043

Li, W., Hardesty, D. M., Craig, A. W., and Song, L. (2022). Hidden price promotions: could retailer price promotions backfire? J. Retail. Consumer Serv. 64:102797. doi: 10.1016/j.jretconser.2021. 102797

Lim, X. J., Cheah, J. H., Ng, S. I., Basha, N. K., and Liu, Y. (2021). Are men from Mars, women from Venus? Examining gender differences towards continuous use intention of branded apps. J. Retail. Consumer Serv. 60:102422. doi: 10.1016/j.jretconser.2020.102422

Marian, Z. (2021). eConsumers Still Prefer in-Store Shopping. Available online at: https://retailleader.com/consumers-still-prefer-store-shopping (accessed November 03, 2021).

Mehrabian, A., and Russell, J. A. (1974). An Approach to Environmental Psychology. Cambridge: The MIT Press.

Memon, M. A., Ting, H., Cheah, J. H., Thurasamy, R., Chuah, F., and Cham, T. H. (2020). Sample size for survey research: review and recommendations. J. Appl. Struct. Equation Model. 4, i-xx. doi: 10.47263/JASEM.4(2)01

Mishra, S., Malhotra, G., and Tiwari, S. R. (2021). Moderating effect of cognitive conflict on the relationship between value consciousness and online shopping cart abandonment. Int. Rev. Retail Distribution Consumer Res. 31, 511-530. doi: 10.1080/09593969.2021.2002386
Nelson, R. A., Cohen, R., and Rasmussen, F. R. (2007). An analysis of pricing strategy and price dispersion on the internet. East. Econ. J. 33, 95-110. doi: $10.1057 /$ eej.2007.6

Nitzl, C., Roldan, J. L., and Carrion, G. C. (2016). Mediation analysis in partial least squares path modelling: helping researchers discuss more sophisticated models. Indus. Manage. Data Syst. 116, 1849-1864. doi: 10.1108/IMDS-07-2015-0302

Paterson, B. (2020). How to Cut Cart Abandonment in the Time of COVID. Available online at: https://www.mytotalretail.com/article/how-to-cut-cartabandonment-in-the-time- of-covid/ (accessed November 02, 2021).

Paz, M. D. R., and Delgado, F. J. (2020). Consumer experience and omnichannel behavior in various sales atmospheres. Front. Psychol. 11:1972. doi: $10.3389 /$ fpsyg.2020.01972

Peng, N., and Chen, A. (2019). Luxury hotels going green-the antecedents and consequences of consumer hesitation. J. Sustain. Tourism 27, 1374-1392. doi: 10.1080/09669582.2019.1622710

Podsakoff, P. M., MacKenzie, S. B., Lee, J. Y., and Podsakoff, N. P. (2003). Common method biases in behavioral research: a critical review of the literature and recommended remedies. J. Appl. Psychol. 88:879. doi: 10.1037/0021-9010.88.5.879

Rajagopal (2019). Consumer behavior: external factors. Contemporary Marketing Strategy (Cham: Palgrave Macmillan). 35-63.

Rajamma, R. K., Paswan, A. K., and Hossain, M. M. (2009). Why do shoppers abandon shopping cart? Perceived waiting time, risk, and transaction inconvenience. J. Product Brand Manage. 18, 188-197. doi: $10.1108 / 10610420910957816$

Raman, P. (2019). Understanding female consumers' intention to shop online: the role of trust, convenience and customer service. Asia Pacific J. Market. Logistics 31, 1138-1160. doi: 10.1108/APJML-10-2018-0396

Rapp, A., Baker, T. L., Bachrach, D. G., Ogilvie, J., and Beitelspacher, L. S. (2015). Perceived customer showrooming behavior and the effect on retail salesperson self-efficacy and performance. J. Retail. 91, 358-369. doi: 10.1016/j.jretai.2014.12.007

Raydiant (2021). The State of Consumer Behavior 2021. Available online at: https://www.raydiant.com/blog/state-of-consumer-behavior-2021/ (accessed November 05, 2021).

Ringle, C. M., Wende, S., and Becker, J. M. (2015). SmartPLS 3. Boenningstedt: SmartPLS GmbH.

Rubin, D., Martins, C., Ilyuk, V., and Hildebrand, D. (2020). Online shopping cart abandonment: a consumer mindset perspective. J. Consumer Market. 37, 487-499. doi: 10.1108/JCM-01-2018-2510

Sarstedt, M., and Cheah, J. H. (2019). Partial Least Squares Structural Equation Modeling Using SmartPLS: A Software Review. 7, 196-202. doi: 10.1057/s41270-019-00058-3

Saunders, M., Lewis, P., and Thornhill, A. (2012). Research Methods for Business Students (6. utg.). Essex, Harlow: Pearson.

Schrift, R. Y., Netzer, O., and Kivetz, R. (2011). Complicating choice. J. Market. Res. 48, 308-326. doi: 10.1509/jmkr.48.2.308

Sembada, A. Y., and Koay, K. Y. (2019). How perceived behavioral control affects trust to purchase in social media stores. J. Bus. Res. 130, 574-582. doi: 10.1016/j.jbusres.2019.09.028

Shmueli, G., Sarstedt, M., Hair, J. F., Cheah, J. H., Ting, H., Vaithilingam, S., et al. (2019). Predictive model assessment in PLS-SEM: guidelines for using PLSpredict. Eur. J. Mark. 53, 2322-2347. doi: 10.1108/EJM-02-2019-0189

Song, J. D. (2019). A study on online shopping cart abandonment: a product category perspective. J. Internet Commerce 18, 337-368. doi: 10.1080/15332861.2019.1641782

Srinivasan, S. S., Anderson, R., and Ponnavolu, K. (2002). Customer loyalty in ecommerce: an exploration of its antecedents and consequences. J. Retail. 78, 41-50. doi: 10.1016/S0022-4359(01)00065-3

Statista (2021a). Number of Online Shoppers in China From 2009 to 2020. Available online at: https:/www.statista.com/statistics/277391/number-ofonline-buyers-in-china/ (accessed November 03, 2021).

Statista (2021b). Penetration Rate of Online Shopping in China From 2010 to 2020. Available online at: https://www.statista.com/statistics/302071/chinapenetration-rate-of-online-shopping/ (accessed November 03, 2021).

Tandon, U., Kiran, R., and Sah, A. N. (2016). Customer satisfaction using website functionality, perceived usability and perceived usefulness towards online shopping in India. Information Dev. 32, 1657-1673. doi: $10.1177 / 0266666915621106$ 
Tian, J., Chen, R., and He, F. (2019). Forgo or go for one? The unavailable effect in non-comparable choice sets. Front. Psychol. 10:1257. doi: 10.3389/fpsyg.2019.01257

Tu, H., and Zhou, X. (2012). Research on the relationship between product prices and migration paths of consumer channels. Modern Manage. Sci. 12, 18-21.

Verhoef, P. C., Kannan, P. K., and Inman, J. J. (2015). From multi-channel retailing to omni-channel retailing: introduction to the special issue on multi-channel retailing. J. Retail. 91, 174-181. doi: 10.1016/j.jretai.2015.02.005

Walsh, G., and Mitchell, V. W. (2010). The effect of consumer confusion proneness on word of mouth, trust, and customer satisfaction. Eur J Mark. 44, 838-859. doi: 10.1108/03090561011032739

Wang, S., Cheah, J. H., Lim, X. J., Leong, Y. C., and Choo, W. C. (2022). Thanks COVID-19, I'll reconsider my purchase: can fear appeal reduce online shopping cart abandonment? J. Retail. Consumer Serv. 64:102843. doi: 10.1016/j.jretconser.2021.102843

Wollenburg, J., Holzapfel, A., Hübner, A., and Kuhn, H. (2018). Configuring retail fulfillment processes for omni-channel customer steering. Int. J. Electronic Commerce 22, 540-575. doi: 10.1080/10864415.2018.1485085

Wong, J. Y., and Yeh, C. (2009). Tourist hesitation in destination decision making. Ann. Tourism Res. 36, 6-23. doi: 10.1016/j.annals.2008.09.005

Wong, Y. T., Osman, S., Jamaluddin, A., and Yin-Fah, B. C. (2012). Shopping motives, store attributes and shopping enjoyment among Malaysian youth. J. Retail. Consumer Serv. 19, 240-248. doi: 10.1016/j.jretconser.2012.01.005

$\mathrm{Xu}$, Y., and Huang, J. S. (2015). Factors influencing cart abandonment in the online shopping process. Soc. Behav. Personal. 43, 1617-1627. doi: 10.2224/sbp.2015.43.10.1617

Yuan, S., Liu, L., Su, B., and Zhang, H. (2020). Determining the antecedents of mobile payment loyalty: cognitive and affective perspectives. Electron. Commer. Res. Appl. 41:100971. doi: 10.1016/j.elerap.2020.100971
Zhang, Y., Xiao, C., and Zhou, G. (2020). Willingness to pay a price premium for energy-saving appliances: role of perceived value and energy efficiency labeling. J. Clean. Prod. 242:118555. doi: 10.1016/j.jclepro.2019.118555

Zhao, H., Wang, X., and Jiang, L. (2021). To purchase or to remove? Online shopping cart warning pop-up messages can polarize liking and purchase intention. J. Bus. Res. 132, 813-836. doi: 10.1016/j.jbusres.2020.10.067

Zheng, X., Men, J., Yang, F., and Gong, X. (2019). Understanding impulse buying in mobile commerce: an investigation into hedonic and utilitarian browsing. Int. J. Inf. Manage. 48, 151-160. doi: 10.1016/j.ijinfomgt.2019. 02.010

Conflict of Interest: The authors declare that the research was conducted in the absence of any commercial or financial relationships that could be construed as a potential conflict of interest.

Publisher's Note: All claims expressed in this article are solely those of the authors and do not necessarily represent those of their affiliated organizations, or those of the publisher, the editors and the reviewers. Any product that may be evaluated in this article, or claim that may be made by its manufacturer, is not guaranteed or endorsed by the publisher.

Copyright (c) 2022 Wang, Ye, Ning, Cheah and Lim. This is an open-access article distributed under the terms of the Creative Commons Attribution License (CC BY). The use, distribution or reproduction in other forums is permitted, provided the original author(s) and the copyright owner(s) are credited and that the original publication in this journal is cited, in accordance with accepted academic practice. No use, distribution or reproduction is permitted which does not comply with these terms. 


\section{APPENDIX}

Appendix 1 | Measurement items.

No. Items

\section{Wait for lower price}

1) I decide to wait for the item to come on sale before buying it.

2) I decide that I may be able to find better sales at another online store.

3) I decide that I may be able to find better sales at a land-based store.

\section{Hesitation at checkout}

1) I have hesitated to complete the checkout stage for selected items while shopping using my online device.

2) It has taken some time for me to click the final payment button to purchase products via an online device.

3) I have thought twice at the checkout stage for a purchase via an online device.

4) I have spent some time deciding whether to press the payment button in an online shopping task.

5) I have waited awhile thinking about whether to finish the checkout process for items in the final payment stage.

Online shopping cart abandonment

1) How often do you place an item in the shopping cart, but do not buy it during the same session?

2) How often do you close the web-page, or log off the online shopping application before you buy the item(s) in your shopping cart?

3) How often do you abandon your online shopping cart?

4) How often do you leave items in your online shopping cart without buying them?

\section{Decision to buy from a land-based retailer}

1) I search/view products online and then purchase products in the physical store.

2) I often visit from online shopping for products and examine product characteristics at physical store.

3) After visiting a product from online platform, I check the availability of products at the physical store and make a purchase at physical store.

4) I use a mobile internet device to fetch information about discount/promotion offers at physical stores.

\section{Perceived transaction inconvenience}

1) The online shop required me to register before making a purchase.

2) The order forms were very lengthy.

3) I got logged off in the middle and had to go through the entire process of completing information again.

4) Technical glitches in the site made the transaction difficult.

\section{References}

Kukar-Kinney and Close, 2010

Cho et al., 2006; Wong and Yeh, 2009

Kukar-Kinney and Close, 2010; Huang et al., 2018

Rapp et al., 2015

Rajamma et al., 2009 